\title{
Molecular Diagnosis and Characterization of Bacillus subtilis Isolated from Burn Wound in Iran
}

\author{
Fatemeh Saleh ${ }^{1}$, Farnaz Kheirandish ${ }^{2}$, Hossein Azizi ${ }^{3 *}$, Maryam Azizi $^{4}$ \\ ${ }^{1}$ Razi Herbal Medicines Research Center, Lorestan University of Medical Sciences, Khorramabad, Iran. \\ ${ }^{2}$ Department of Parasitology and Mycology, Razi Herbal Medicines Research Center, Lorestan University of Medical Sciences, Khorramabad, \\ Iran. \\ ${ }^{3}$ Departement of Microbiology, Islamic Azad University, Borujerd branch, Borujerd, iran, Razi Herbal Medicines Research Center, Lorestan \\ University of Medical Sciences, Khorramabad, Iran. \\ ${ }^{4}$ Departement of Microbiology, Islamic Azad University, Yazd Branch, Yazd, Iran.
}

Received: 19 Mar 2014

Revised : 25 Apr 2014

Accepted: 17 May 2014

Corresponding Authors:

Hossein Azizi

Departement of Microbiology, Islamic

Azad University, Borujerd Branch,

Borujerd, Iran, Razi Herbal Medicines

Research Center, Lorestan University

of Medical Sciences, Razi st,

Khorramabad, Iran.

Phone: +98-9168603925

E-mail:Azizihosein23@yahoo.com

\begin{abstract}
Background: Bacillus subtilis refers to stretched and sometimes curved, grampositive, aerobic, and catalase-positive bacilli, which has thermo-resistant endospores. It has been known as a normal flora in the human but can be pathogens In the case of opportunistic. Also, it can be the pathogen of nosocomial infections such as wound among hospitalized patients. Purpose of this study was to identify the type of nosocomial infections in a burn patient suffering from wound infections and septicemia.
\end{abstract}

Materials and Methods: In November 2012, sampling was made from the burn wound of a 26-year-old woman infected with septicemia using a sterile swab. The wound sample was cultured on a blood agar medium. Various routine biochemical tests were performed for species detection and identification. Eventually, PCR was used to increase the reliability and accuracy in the identification of the isolated bacterium. The PCR product was then sequenced.

Results: According to the results of different biochemical tests and molecular identification, the bacteria separated from B. subtilis wound were reported. The mentioned gene was recorded under access number AB894357 in the gene bank.

Conclusion: According to the conducted studies, although $B$. subtilis is known as a commensal bacterium, it can be considered a pathogen of nosocomial infection, which subsequently causes secondary infections. Considering that $B$. subtilis is known as a nonpathogenic bacterium, it is recommended to pay more attention to its diagnosis and treatment as an opportunistic pathogen among hospitalized patients.

Keywords: Bacillus subtilis; Nosocomial infection; PCR

Please cite this article as: Saleh F, Kheirandish F, Azizi H, Azizi M. Molecular Diagnosis and Characterization of Bacillus subtilis Isolated from Burn Wound in Iran. Res Mol Med. 2014; 2 (2): 40-44

\section{Introduction}

Bacillus subtilis is stretched and chained bacilli with the size of $0.8-0.7 / 2-3 \mathrm{um}$, which is gram-positive, aerobic, non-encapsulated, mobile, and spore-bearing and is widely found in the nature. Colonies of this bacterium have a white or slightly yellowish, rough and opaque surface and grow in the mesophilic temperature range of $25-35^{\circ} \mathrm{C}(1-2)$. Also, its active form is usually in the shape of spores. Because of having spores, it has a set of strategies that allows for survival in harsh conditions. For example, formation of endospores against stress provides the bacterium with compatibility with food poverty, acidic, alkaline, or osmotic situations, or oxidative conditions of heat or ethanol (3). In genetic studies, it is used for purine nucleotide synthesis pathway. These nucleotides are involved as energy carriers in the structure of NAD, FAD, adenosyl methionine, and coenzyme A cofactors and also activated biosynthetic intermediate 
compounds such as UDP-glucose and CDP-glycerol. Some of these compounds such as cAMP and cGMA act as secondary messengers (4). Another strategy is the absorption of external DNA, which allows the bacterium to correspond to the recombination, which is time-consuming. This bacterium is a good model for cellular development and differentiation (4). It is the antibiotic producer of Subtilin (4).

Table 1. Various biochemical tests to distinguish different species of bacillus: (+) 85-100\% positive, (-) 0-014\% positive, (v) variable and (w) weak.

\begin{tabular}{|c|c|c|c|c|c|c|c|c|c|c|}
\hline & 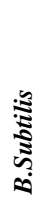 & 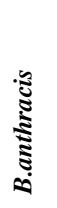 & 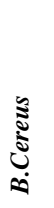 & 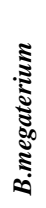 & 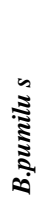 & 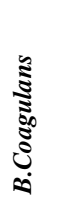 & 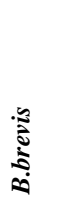 & 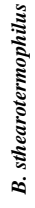 & 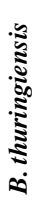 & 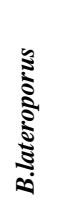 \\
\hline Motility & + & - & + & + & + & + & + & + & + & + \\
\hline \multicolumn{11}{|l|}{ Spore: } \\
\hline Terminal/sub terminal & - & - & - & - & - & - & $\mathrm{v}$ & + & - & - \\
\hline Central/paracentral & + & + & + & + & + & $\mathrm{v}$ & + & - & + & + \\
\hline Anaerobic growth & - & + & + & - & - & + & - & - & + & + \\
\hline Citrate utilization & + & $\mathrm{w}$ & + & $\mathrm{w}$ & + & w & $\mathrm{w}$ & - & - & + \\
\hline VP Reaction & + & + & + & - & + & $\mathrm{v}$ & - & - & + & - \\
\hline Indol & - & $\mathrm{v}$ & + & - & - & - & - & + & + & - \\
\hline Lecithinase & + & + & + & - & - & - & - & - & - & + \\
\hline \multicolumn{11}{|l|}{ Growth in: } \\
\hline $45^{0} \mathrm{c}$ & + & - & + & + & + & + & + & + & $\mathrm{w}$ & + \\
\hline Urase & - & - & - & + & - & - & - & - & + & + \\
\hline Starch hydrolysis & + & + & + & + & - & + & - & + & - & - \\
\hline Gelatin hydrolysis & + & + & + & + & + & - & - & + & - & - \\
\hline Acid From: & + & - & - & + & + & + & - & $\mathrm{w}$ & + & - \\
\hline Lactose & - & - & - & + & - & - & - & + & + & + \\
\hline Glucose & + & + & + & + & + & + & + & + & + & + \\
\hline Maltose & + & + & + & + & + & + & - & + & + & - \\
\hline Arabinose & + & - & - & + & + & + & - & - & $\mathrm{w}$ & + \\
\hline Xylose & + & - & - & + & + & + & $\mathrm{w}$ & + & + & + \\
\hline Sucrose & + & + & $\mathrm{v}$ & + & + & + & + & + & $\mathrm{v}$ & - \\
\hline ONPG actvity & + & - & - & + & + & $\mathrm{v}$ & $\mathrm{w}$ & + & + & + \\
\hline
\end{tabular}

Amylase, protease, lipase, chitinase, and inosine are the important enzymes secreted in this bacterium, through which it can be pathogenic to plants and humans in appropriate conditions (4). It is naturally 
found in soil and vegetation. In plants, it is used as a fungicide due to producing chitinase (4-5). B. subtilis is one of the nonpathogenic bacteria, which exists as a normal flora in the human gastrointestinal system (6). It can induce disorder in mammalian membrane systems due to the production of lecithinase enzyme in opportunistic cases. Moreover, it produces an extracellular toxin c alled Subtilisin that causes allergic reactions in humans (6-7). This bacterium can contaminate food; nevertheless, it rarely causes food poisoning (6-7). Few reports have been presented about the pathogenesis of B. subtilis in humans.

Also, some reports have been presented about endocarditis in infants (8). In the patients with the impaired immune system, it causes bacteremia (8-9).

Table 2. Examining sensitivity to antibiotics in isolated B. subtilis from the wound of hospitalized burn patient in Shohadaye Ashayer Hospital, City of Khorramabad, Lorestan Province, Iran, in 2012, (S), Susceptible, (R)Resistant

\begin{tabular}{lll}
\hline Antibiotic & Disk content $(\boldsymbol{\mu g})$ & Susceptibility \\
\hline Gentamycin & 10 & $\mathrm{~S}$ \\
Amikacin & 30 & $\mathrm{~S}$ \\
Imipenem & 10 & $\mathrm{~S}$ \\
Ampicilin & 10 & $\mathrm{~S}$ \\
Tetracyclin & 30 & $\mathrm{~S}$ \\
Co-trimoxazol & $1.25 / 23.75$ & $\mathrm{~S}$ \\
Cefteriaxone & 30 & $\mathrm{~S}$ \\
Vancomycin & 30 & $\mathrm{~S}$ \\
Cefotaxim & 30 & $\mathrm{R}$ \\
Cefixime & 30 & $\mathrm{R}$ \\
\hline
\end{tabular}

Further, it is one of the important factors in the contamination of laboratory media (7). In hospitals, it is considered one of the pathogens of nosocomial infection; for example, patients undergoing surgery may be infected with secondary infections due to the spread of the spores of this bacterium (6-9). Therefore, in this study, B. subtilis was isolated from the wound of a burn patient, who was infected with this bacterium in the hospital. Thus, in addition to biochemical tests, molecular methods were used for certainty in the results.

\section{Materials and Methods}

In November 2012, a 26-year-old patient woman was hospitalized in Shohadaye Ashayer Hospital, city of Khorramabad, Lorestan, Iran. The patient was suffering from third-degree burning and the burn wounds had inflammation, swelling, pain, and bleeding. There was also necrotic tissue around the wound. Infected wound was in a granular state with infectious secretions (Figure 1). The patient underwent septicemia after the wound infection. Wound sampling was done by a sterile swab and inoculated into Stuart's transport medium. Then, the wound sample was cultured on blood agar medium. After 24 hours of incubating the media at $37{ }^{\circ} \mathrm{C}$ both in $5 \% \mathrm{CO}_{2}$ as well as aerobic conditions, diagnostic tests were performed for the identification purposes (10-11). After examining the bacterium in terms of morphology, several biochemical tests were performed for more investigations. These tests included catalase, oxidase, ortho-Nitrophenyl- $\beta$-galactoside (ONPG), motility, investigating spore position, Voges-Proskauer (VP) reaction, urease and citrate consumption, growth in anaerobic conditions, starch hydrolysis, gelatin hydrolysis, growth in $7 \% \mathrm{NaCl}$, growth at 45 ${ }^{\circ} \mathrm{C}$, lecithinase production, indole production, acid production from glucose, lactose, arabinose, maltose, sucrose, xylose and mannitol (10-11).

\section{Amplification of $16 S$ rRNA gene sequence}

In this study, PCR method was used for more precise identification. DNA was extracted using DNA extraction protocol, DNG Plus kit (Cinnagen; Tehran, Iran). A part of the primer universal $16 \mathrm{~S}$ rRNA gene sequence was amplified according to the studies that had been previously performed: Forward, RW01 (5AACTGGAGGAAGGTGGGGAT-3) and Reverse, DG74 (5-AGGAGGTGATCCAACCGCA-3) (12). Electrophoresis of the PCR product along with weight marker was loaded on the $1 \%$ agarose gel (12). 


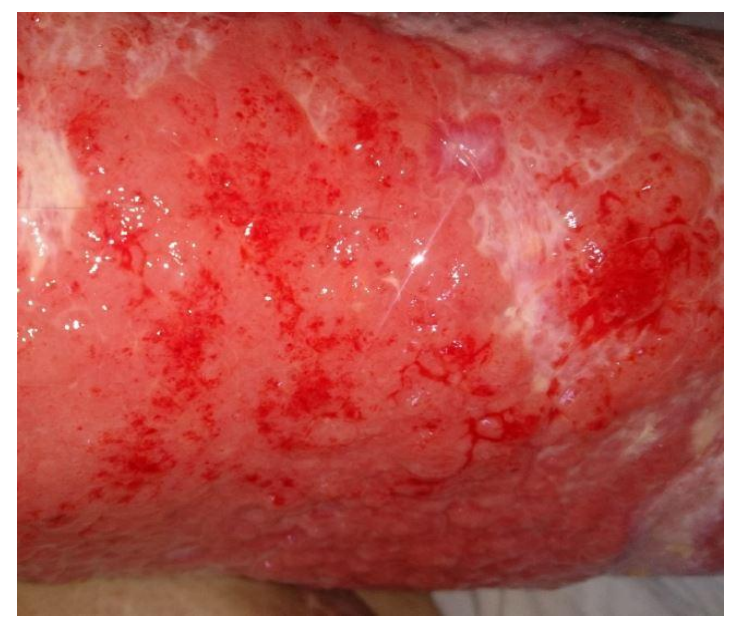

Figure 1. Infected burn wound with granulation tissue in the 26year-old woman in Shohadaye Ashayer Hospital, city of Khorramabad, Lorestan, Iran

Sequencing and performing BLAST on the sequences For certainty of the diagnosis, the PCR product was sequenced. The obtained sequences were compared with the sequences reported in the gene bank.

\section{Results}

The obtained PCR product had a 370 bp specific band on the gel (Figure 2). Blast result of the sequenced PCR product showed 99\% homology in the target gene with the strain of $B$. subtilis recorded in the gene bank. The considered gene was recorded under access number AB894357 in the gene bank.

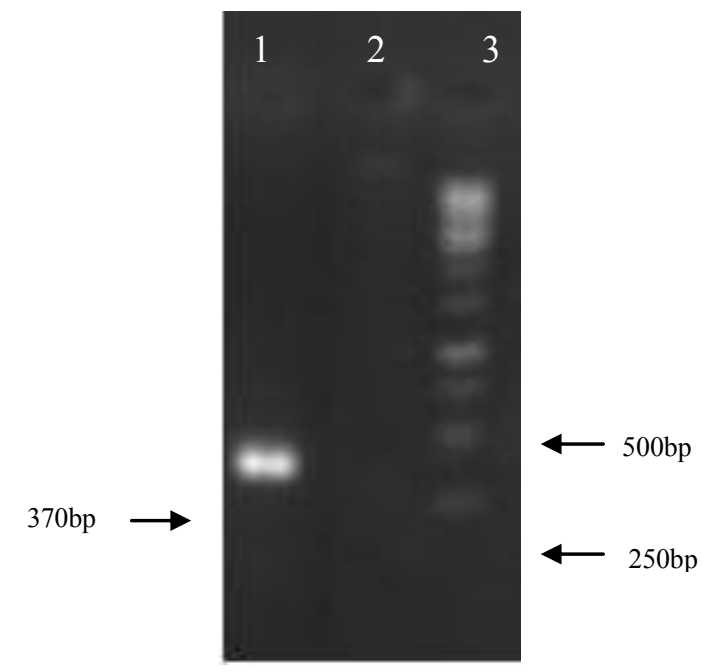

Figure 2. Electrophoresis of the PCR product of isolated 16S rRNA gene from the wound of the burn patient on $1 \%$ agarose gel in Shohadaye Ashayer Hospital, city of Khorramabad, Lorestan Province, in 2012

Column 1: 370 bp specific band from the 16S rRNA gene of $B$. subtilis isolated from the burn patient of Shohadaye Ashayer Hospital, city of Khorramabad, Lorestan Province, Iran, 2012

Column 2: Negative control

Column 3: 1000 bp DNA ladder marker
The obtained colonies in the medium were in large, rough, wrinkled, and beta-hemolytic forms. Test results contained positive-catalase and negativeoxidase (Table 1). After performing different biochemical tests, B. subtilis was separated from the wound. Antibiogram test using disk diffusion method according to CLSLI for the antibiotic discs was as follows: the bacterium was sensitive to gentamicin, amikacin, imipenem, ampicillin, tetracycline, sulfamethoxazole, ceftriaxone, and vancomycin and resistant to cefotaxime and cefixime (Table 2)

\section{Discussion}

Nonpathogenic bacteria may occasionally cause serious diseases or even fatality in humans. Most of infectious cases have been reported to have such factors. B. subtilis can be noted as one of these bacteria, which are associated with human infections (8-9) and consists of gram-positive, rod-shaped bacteria classified as bacillus. Laboratories generally do not pay great attention to the diagnosis of various species, except $B$. anthracis, because they are not pathogenic (9). Although B. subtilis is known as a commensal bacterium in the human intestine and normal flora in animals and plants, it is an important factor for generating nosocomial infections, especially secondary wound infections (4-5). This bacterium has amylase, protease, lipase, chitinase, and adenosine enzymes (4-5). According to the previous studies, similar to other bacillus, B. subtilis as an opportunistic bacterium is considered as one of the factors for causing gastroenteritis and food poisoning like B. cereus (13-14). But, this bacillus has been mostly considered as the cause of secondary infections such as septicemia and meningitis $(8-9,13-$ 15). In patients with the impaired immune system, it may be problematic and finally cause cancer $(11,13)$. Considering this bacterium as a contaminant can also cause secondary infections as well as diseases. This issue has an important effect on the progress of nosocomial infections in hospitals and medical centers, which can lead to antibiotic resistance that is considered a problem in the treatment of infectious diseases. In this study, B. subtilis which was isolated from the wound of a burn patient was considered as a nosocomial infection and blood culture test confirmed that the patient had septicemia in addition to wound infection; this point indicated that the prevalence of this bacterium was one of the risk factors in hospitals $(11,16-17)$. Therefore, it is recommended to be more accurate in the investigation and interpretation of infectious culturing despite the uncommon signs of bacteria, especially $B$. subtilis. Also, based on the pathogenesis of this bacteria this bacterium in desirable conditions and the following antibiotic resistance, it should not 
be considered a contaminant in the interpretation of microbial culturing. Nowadays, development of modern genetic transmission of new strains and also resistant strains has highlighted the importance of the diagnosis of $B$. subtilis and its treatment as a pathogen in hospitals $(6-7,16-17)$. Therefore, the aim of this study was to identify of Bacillus subtilis by molecular and biochemical methods were, because less attention to it as a nosocomial infection.

\section{Conclusions}

B. subtilis is generally known as normal flora in humans and animals. It is considered as a medium contaminant in laboratory environments which is due to the spread of spores. Considering the above points, the conclusion was made that $B$. subtilis is a nosocomial infection and could cause secondary diseases and infections such as bacteremia, septicemia, and wound infection in hospitalized patients, especially patients who have the impaired immune system.

\section{Acknowledgment}

Hereby, a respected management and colleagues Razi Herbal Medicines Research Center, Lorestan University of Medical Sciences for cooperation is sincerely appreciated. Also, of all the people who helped us in this project comes to appreciate.

\section{References}

1. Logan NA, Popovic T, Hoffmaster A. Bacillus and other aerobic endospore-forming bacteria. Manual Clin Microbiol. 2009; 9: 45573.

2. Logan NA, Turnbull PCB PR, Baron JE, Pfaller Murray. Bacillus and other aerobic endospore-forming bacteria. In: MA, Tenover FC, Yolken RH, edithors. Manual Clin Microbiol. Washington: ASM Press; 2003.p. 445-60.

3. Liu Y, Guan Y, Yang Z, Cai Z, Mizuno T, Tsuno H, et al. Toxicity of seven phthalate esters to embryonic development of the abalone Haliotisdiversi color supertexta. Ecotoxicology. 2009; 18 (3): 293-303. PMID: 19030987

4. Bais HP, Fall R, Vivanco JM. Biocontrol of Bacillus subtilis against infection of Arabidopsis roots by Pseudomonas syringae is facilitated by biofilm formation and surfactin production. Plant Physiol. 2004; 134(1): 307-19. PMID: 14684838

5. Mead PS, Slutsker L, Dietz V, McCaig LF, Bresee JS, Shapiro $\mathrm{C}$, et al. Food related illness and death in the Unite States. Emer Infect Dis. 1999; 5(5):607-25. PMID: 10511517
6. Nicolas P, Mader U, Dervyn E, Rochat T, Leduc A, Pigeonneau $\mathrm{N}$, et al. Condition-dependent transcriptome reveals high-level regulatory architecture in Bacillus subtilis. Science. 2012; 335(6072): 1103-6. PMID: 22383849

7. Saris P, Taira S, Airaksinen U, Palva A, Sarvas M, Palva I, Runeberg-Nyman K. Production and secretion of pertussis toxin subunits in Bacillus subtilis. FEMS Microbiol Lett. 1990; 56(1-2): 143-8. PMID: 2110091

8. Oggioni MR, Pozzi G, et al. Recurrent Septicemia in an Immunocompromised Patient Due to Probiotic Strains of Bacillus subtilis. J Clin Microbiol. 1998; 36 (1): 325-6. PMID: 9431982

9. Weinstein L, Charles MD, Colburn G, Meningitis MD, BACTEREMIA,Report of a Case and Review of the Literature on "Subtilis" Infections in Man. AMA Arch Intern Med. 1950; 86(4):585-94. PMID:14770583

10. Claus D, Berkeley RCW. 1986. Genus Bacillus Cohn. In: PHA Sneath, et al. edithors. Bergey's Manual of Systematic Bacteriology. Baltimore: Williams and Wilkins Co.; 1872. p. 1105-1139

11. Weber DJ, Saviteer SM, Rutala WA, Thomann CA. Clinical significance of Bacillus species isolated from blood cultures. South Med J. 1989; 82(6): 705-9. PMID: 2499933

12. Mellmann A, Cloud J, Maier T, Keckevoet U, Ramminger I, Iwen $\mathrm{P}$, et al. Evaluation of matrix-assisted laser desorption ionization-time-off light, mass spectrometry in comparison to $16 \mathrm{~S}$ rRNA gene sequencing, J Clin Microbiol. 2008; 46 (6): 1946-54. PMID: 18400920

13. Tauzon CU, Murray HW, Levy C, Solny MN, Curtin JA, Sheagren JN, Serious infections from Bacillus species. JAMA. 1979; 241:1137-40. PMID: 105158

14. Wallet F, Crunelle V, Roussel-Delvallez M, Furchard A, Saunier P, Courcol RJ. Bacillus subtilis as a cause of cholangitis in polycystic kidney and liver disease. Am J Gastroenterol. 1996; 91(7): 1477-8. PMID: 8678036

15. Thomas M, Whittet H. Atypical meningitis complicating a penetrating head injury. J Neurol Neurosurg Psychiatry. 1991; 54(1): 92-3. PMID: 1901352

16. de Boer AS, Diderichsen B. On the safety of Bacillus subtilis and B. amyloliquefaciens: a review. Appl Microbiol Biotechnol. 1991; 36(1): 1-4. PMID: 1367772

17. Kiss T, Gratwohl A, Frei R, Osterwalder B, Tichelli A, Speck B. Bacillus subtilis infections. Schweiz Rundsch Med Prax. 1988; 77(45): 1219-23. PMID: 3142006 